\title{
LIQUEFACTION OF CROP RESIDUES FOR POLYOL PRODUCTION
}

\author{
Lingyun Liang, ${ }^{\text {a }}$ Zhihuai Mao,${ }^{a^{*}}$ Yebo Li ${ }^{\mathrm{b}}$ Caixia Wan ${ }^{\mathrm{b}}$, Tipeng Wang, ${ }^{\mathrm{a}}$ Lianhui Zhang, ${ }^{\mathrm{a}}$ \\ Lingyan Zhang ${ }^{\mathrm{a}}$
}

The liquefaction of crop residues in the presence of ethylene glycol, ethylene carbonate, or polyethylene glycol using sulfuric acid as a catalyst was studied. For all experiments, the liquefaction was conducted at $160^{\circ} \mathrm{C}$ and atmospheric pressure. The mass ratio of feedstock to liquefaction solvents used in all the experiments was 30:100. The results show that the acid catalyzed liquefaction process fit a pseudo-first-order kinetics model. Liquefaction yields of 80,74 , and $60 \%$ were obtained in 60 minutes of reaction when corn stover was liquefied with ethylene glycol, a mixture of polyethylene glycol and glycerol $(9: 1, w / w)$, and ethylene carbonate, respectively. When ethylene carbonate was used as solvent, the liquefaction yields of rice straw and wheat straw were $67 \%$ and $73 \%$, respectively, which is lower than that of corn stover $(80 \%)$. When a mixture of ethylene carbonate and ethylene glycol $(8: 2, \mathrm{w} / \mathrm{w})$ was used as solvent, the liquefaction yields for corn stover, rice straw and wheat straw were 78,68 , and $70 \%$, respectively.

Keywords: Corn stover, Wheat straw, Rice straw, Liquefaction, Polyol

Contact information: a: College of Engineering, China Agricultural University 17 Qinghua Donglu, Beijing 100083, China, E-mail: maozhh@cau.edu.cn; b: Biological Engineering Program, North Carolina A\&T State University, 1601 East Market Street, Greensboro, NC 27411, E-mail: yli@ncat.edu; *Corresponding author:maozhh@cau.edu.cn,yli@ncat.edu

\section{INTRODUCTION}

Crop residues such as corn stover, wheat straw, and rice straw are abundant biomass resources in China. The amount of agricultural residues produced annually in China is estimated to be about 640 million tons (Anon. 2000). In order to increase the productivity of the land, crop rotation is a widely accepted practice in China. The second crop is immediately seeded after the harvesting of the previous crop. There is no time for the decay of the crop residues that should be removed from the land for better seedbed preparation. Open burning is widely used in the rural area to get rid of the crop residues, and this has aggravated the air pollution problem. On the other side, with the depletion of petroleum, bio-based products made of biomass are required to replace the petroleumbased products. Conversion of crop residues to bio-based products has the potential to be a win-win situation for the agriculture, processing industry, and the environment.

In past decades, biological, thermal, and chemical conversion technologies have been studied to convert lignocellulosic biomass to biofuel and bio-based products. Lignocellulosic biomass could be pretreated and fermented to produce ethanol and chemicals (Kaar and Holtzapple 2000; Kim et al. 2003; Ruan et al. 2004; Shahbazi et al. 2005), and gasified to produce synthesis gas, which is an alternative source of fuel for the 
rural community (Dasappa et al. 2003). In the absence of oxygen, lignocellulosic biomass could be converted to liquids, gases and char with the fast pyrolysis process (Mohan et al. 2006). Lignocellulosic biomass could also be liquefied under acid conditions with liquefying reagents, such as ethylene glycol and ethylene carbonate, to produce polyol products (Yamada and Ono 1999; Yu et al. 2006a). Polyols are chemical compounds containing multiple hydroxyl groups. Some polyesters, polyurethanes, and fuels have been prepared from the liquefied polyol product (Montane et al. 1998; Yu et. al. 2006b).

The hydroxyl groups of the lignocellulosic biomass make it possible to carry out biopolymer production. Liquefaction is an effective method to convert lignocellulosic biomass into intermediates rich in hydroxyl groups. Wood has been successfully liquefied with polyethylene glycol and phenols in Japan to produce polyurethane foams and phenol-formaldehyde resin (Yao et al. 1996). Shiraishi et al. (1992) reported that liquefaction of lignocellulosic biomass can be done in the presence of these organic solvents using either acid catalysts at temperatures of $120-180^{\circ} \mathrm{C}$ or without catalysts at temperatures of $180-250^{\circ} \mathrm{C}$. Phenol and phenol derivatives mixed with small amounts of sulfuric acid could promote the hydrolytic reactions of depolymerisation in the cellulosic chain (Yu 1982). Yu et al. (2006a) reported that corn stover could be converted to biopolyols in the presence of ethylene glycol and ethylene carbonate, using sulfuric acid as a catalyst. However, we have not found any report on the comparison of the liquefaction yield of different types of crop residues.

The liquefied products could be used to produce biopolymers such as epoxy resins, which could be used as packaging and insulation materials and adhesives. As the liquefaction process could release some of the etherified hydroxyl groups and reduce the molecular weight of lignin, the reactivity of lignin can be improved (Xie and Chen, 2005). Yu et al. (2006b) reported that the liquefied corn stover could be directly used as feedstock for making polymers without further separation or purification.

In this present article, we designed the experiments to compare the performance of liquefaction process of different feedstock when different liquefaction agents were used. The liquefied products were also characterized with FTIR spectra. It is helpful for choosing the optimal liquefaction agents for different feedstock. The influence of organic solvents on the liquefaction yield of corn stover was also investigated. A first-order reaction model was then used to analyze the kinetics of the liquefaction process.

\section{EXPERIMENTAL}

\section{Materials}

Corn stover and wheat straw were collected from a local farm in a Beijing suburb and rice straw was collected from the Jiangxi province of China. All of the collected samples with moisture content of $8 \%-10 \%$ were stored in plastic bags at ambient temperature before use. The materials were milled, dried, and screened before tests. Only the fraction with particle size of 20-80 mesh was used for the liquefaction experiments. The compositions of the feedstock were analyzed by Van Soest measurements, using an Ankom Fiber Analyzer (ANKOM220, ANKOM Techno. Corp., NY). The compositions are shown in Table 1. 
Sulfuric acid $(97 \%)$ was used as a catalyst. Ethylene glycol, ethylene carbonate, polyethylene glycol + glycerol $(9: 1, \mathrm{w} / \mathrm{w})$, or ethylene carbonate + ethylene glycol $(8: 2$, $\mathrm{w} / \mathrm{w}$ ) were used as solvent in the liquefaction process. All chemicals used were reagent grade and obtained from commercial sources.

Table 1. Compositions of Feedstocks (dry basis)

\begin{tabular}{ccccc}
\hline Samples & $\begin{array}{c}\text { Ash } \\
\%\end{array}$ & $\begin{array}{c}\text { Cellulose } \\
\%\end{array}$ & $\begin{array}{c}\text { Hemicellulose } \\
\%\end{array}$ & $\begin{array}{c}\text { Acid-insoluble lignin } \\
\%\end{array}$ \\
\hline Corn stover & 5.92 & 34.51 & 23.86 & 6.61 \\
Rice straw & 12.47 & 38.48 & 20.51 & 6.42 \\
Wheat straw & 9.97 & 37.07 & 21.72 & 5.90 \\
\hline
\end{tabular}

\section{Biomass liquefaction}

Liquefying chemicals (50g solvent and $1.5 \mathrm{~g}$ catalyst) were added into a threeneck flask $(250 \mathrm{~mL})$ equipped with a reflux condenser, a thermometer, and a motor-driven stirrer. The flask was then immersed in a silicon oil bath that had been preheated to $160^{\circ} \mathrm{C}$. When the temperature of liquefying chemicals reached $150^{\circ} \mathrm{C}-160^{\circ} \mathrm{C}, 15 \mathrm{~g}$ crop residue samples were added. The mixture was continuously stirred during the liquefaction process to obtain homogeneously liquefied product. For all experiments, the liquefaction was conducted at $160^{\circ} \mathrm{C}$ and in the air at atmospheric pressure. After the preset time, the flask was immersed into cold water to quench the reaction and the liquefied products were collected for later use and analysis.

\section{Analysis}

The amount of residue in the biopolyols after aqueous dioxane extraction and rinsing was measured to evaluate the liquefaction yield. The liquefied biopolyols were extracted using an aqueous dioxane solution (dioxane: $\mathrm{H}_{2} \mathrm{O}, 80: 20$ ). Unliquefied biomass residue was obtained by vacuum-filtration of the extracted solution, using quantitative filter paper (medium speed). The solid residue was then rinsed with the aqueous dioxane solution repeatedly until a colorless filtrate was obtained. The rinsed solid residue was then dried in an oven at $105^{\circ} \mathrm{C}$ for 24 hours to obtain the dry mass of the residue. The liquefaction yield was calculated by:

$$
\text { Liquefaction yield }=\left(1-\frac{d r y \text { mass of solid residue }}{d r y \text { mass of feedstock }}\right) \times 100
$$

Fourier transform infrared (FTIR) spectra of selected samples were obtained using a Perkin-Elmer Spectrum GX spectrometer equipped with DTGS detector. The liquefaction residue was analyzed with a $\mathrm{KBr}$ pelletization method. 


\section{RESULTS AND DISCUSSION}

\section{Effect of Organic Solvent}

Liquefaction of corn stover with three different solvents (ethylene carbonate, ethylene glycol, and a mixture of polyethylene glycol and glycerol) was studied. The average liquefaction yields from three replicate tests with the above three organic solvents are shown in Fig. 1. Among the three liquefying solvents tested, ethylene carbonate was the most effective solvent for corn stover liquefaction. The liquefaction yield reached 80,74 , and $60 \%$ in 60 minutes of reaction, when ethylene carbonate, the mixture of polyethylene glycol and glycerol, and ethylene glycol were used as solvents, respectively. Liquefaction yield of $70 \%$ was obtained in 30 minutes when ethylene carbonate was used as solvent. The difference in liquefaction efficiency among different solvents might be caused by their dielectric constant values (Yamada and Ono 1999). The dielectric constants of ethylene carbonate and ethylene glycol at $40^{\circ} \mathrm{C}$ are 90.5 and 38.4 , respectively (Sengwa, et al., 2000, Chernyak, 2006). The dielectric constant of ethylene carbonate is much higher than that of ethylene glycol. Higher liquefaction yield was obtained when solvent with higher dielectric constant was used. The results of the analysis of variance of liquefaction yield showed that liquefaction solvents have significant effect $(\mathrm{p}<0.0001)$ on the liquefaction yield.

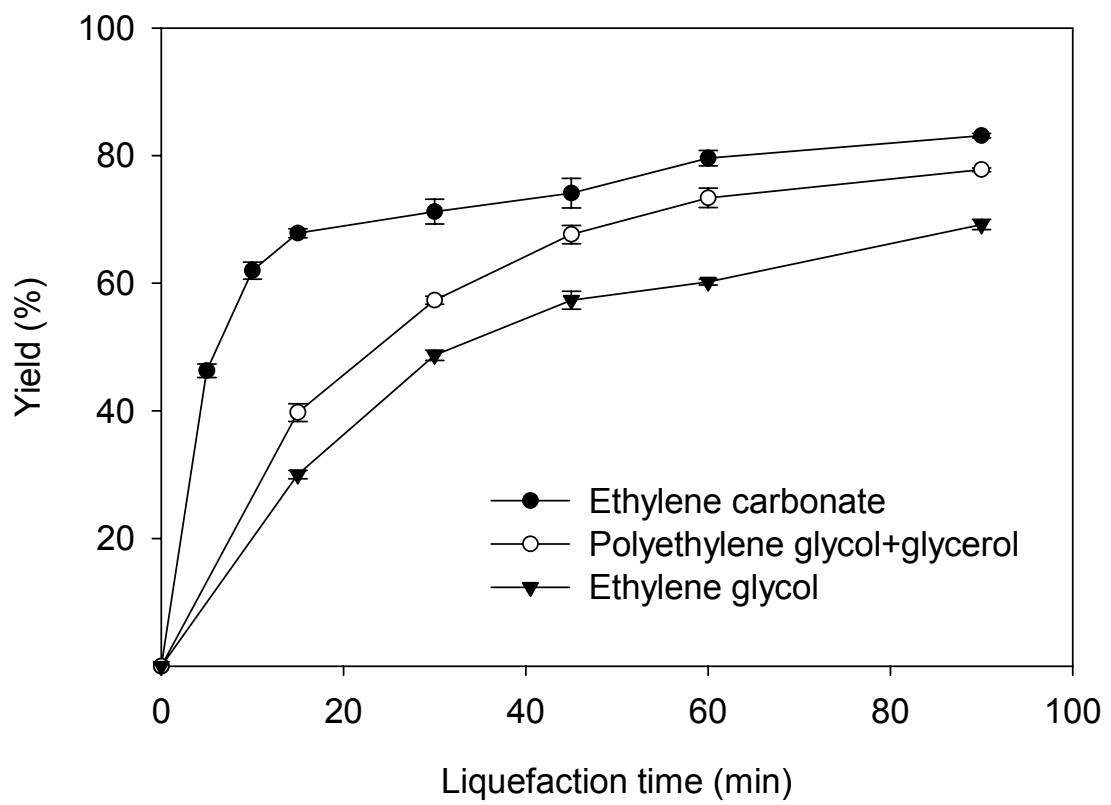

Fig. 1. Liquefaction yield of corm stover with different organic solvents

When the residue was plotted in log scale, there was a linear correlation between $\ln R$ and $t$, which demonstrated that the crop residue liquefaction process follows a pseudo-first-order reaction. The mass of unliquefied crop residue can be expressed as follows:

$$
R=1-\text { yield }=A \exp (-k t)
$$


where $k$ is the rate constant, and $R$ is the mass of unliquefied crop residue. The rate constant is an important parameter to evaluate the reaction rate of the liquefaction process. The values of the constant $k$ for corn stover liquefaction with different liquefying solvents are shown in Table 2.

The highest reaction rate constant of $8.84 \times 10^{-2} / \mathrm{min}$ was obtained when ethylene carbonate was used as solvent. When ethylene glycol and a mixture of polyethylene glycol and glycerol were used as solvent, reaction rate constants of $1.91 \times 10^{-2}$ and $2.49 \times 10^{-2} / \mathrm{min}$ were obtained, respectively, which were much lower than that of ethylene carbonate. The liquefaction rate constant of ethylene carbonate was 3.6 and 2.6 times higher than that of ethylene glycol and mixture of polyethylene glycol and glycerol, respectively.

Table 2. Rate Constants of Corn Stover Liquefaction with Different Liquefying Solvents

\begin{tabular}{lcc}
\hline \multicolumn{1}{c}{ Liquefying solvents } & Rate constant & Correlation coefficient $\left(\mathrm{R}^{2}\right)$ \\
\hline Ethylene carbonate & 0.0884 & 0.9702 \\
Polyethylene glycol + glycerol & 0.0249 & 0.9807 \\
Ethylene glycol & 0.0191 & 0.9815 \\
\hline
\end{tabular}

\section{Effect of Feedstock}

In order to compare the liquefaction yield of different types of crop residues, wheat straw, rice straw, and corn stover were liquefied with ethylene carbonate and a mixture of ethylene carbonate and ethylene glycol $(8: 2, \mathrm{w} / \mathrm{w})$. The liquefaction yield of corn stover, wheat straw, and rice straw with ethylene carbonate are shown in Fig.2. The liquefaction yield reached 80,67 , and $73 \%$ in 60 minutes for corn stover, rice straw, and wheat straw, respectively. The rate constants of rice straw and wheat straw were $7.02 \times 10^{-}$ $2 / \mathrm{min}$ and $5.47 \times 10^{-2} / \mathrm{min}$, which is lower than that of corn stover $\left(8.84 \times 10^{-2} / \mathrm{min}\right)$.

In the previous tests, the liquefaction yield of corn stover only reached $60 \%$ after 60 minutes of liquefaction with ethylene glycol. In order to improve the liquefaction yield, a mixture of ethylene carbonate and ethylene glycol $(8: 2, \mathrm{w} / \mathrm{w})$ instead of ethylene glycol was used to evaluate the liquefaction yield of the studied crop residues. As shown in Fig 3, the liquefaction yield reached 78, 68, and 70\% in 60 minutes of liquefaction for corn stover, rice straw, and wheat straw, respectively when mixture of ethylene carbonate and ethylene glycol was used as solvent. The rate constants of rice straw and wheat straw were $7.56 \times 10^{-2} / \mathrm{min}$ and $6.95 \times 10^{-2} / \mathrm{min}$ respectively. These constants were lower than that of corn stover $\left(8.82 \times 10^{-2} / \mathrm{min}\right)$. A similar pattern was also obtained when ethylene carbonate was used as solvent, as shown in Table 3. 


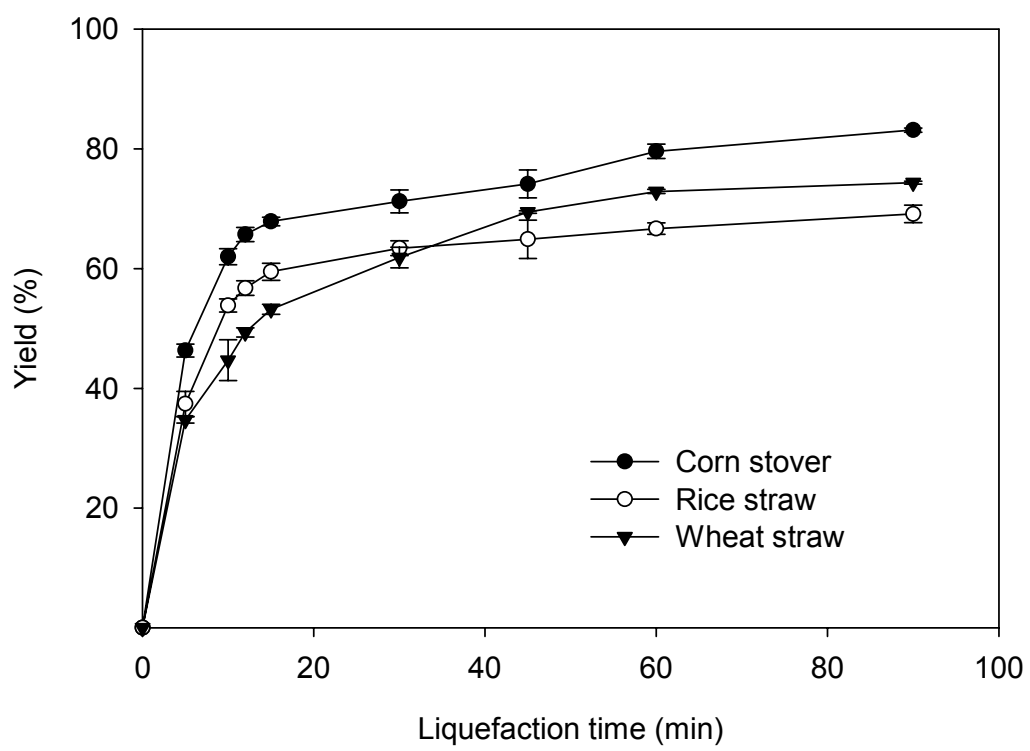

Fig. 2. Liquefaction yield of crop residues when liquefied with ethylene carbonate

For both of the solvents tested, highest liquefaction yield was obtained with corn stover, while the liquefaction yield of rice straw was very close to that of wheat straw. The analysis of variance performed on liquefaction yield showed feedstock had significant $(p<0.0001)$ effects on the liquefaction yield. There was significant interaction between solvent and feedstock on liquefaction yield $(\mathrm{p}=0.001)$.

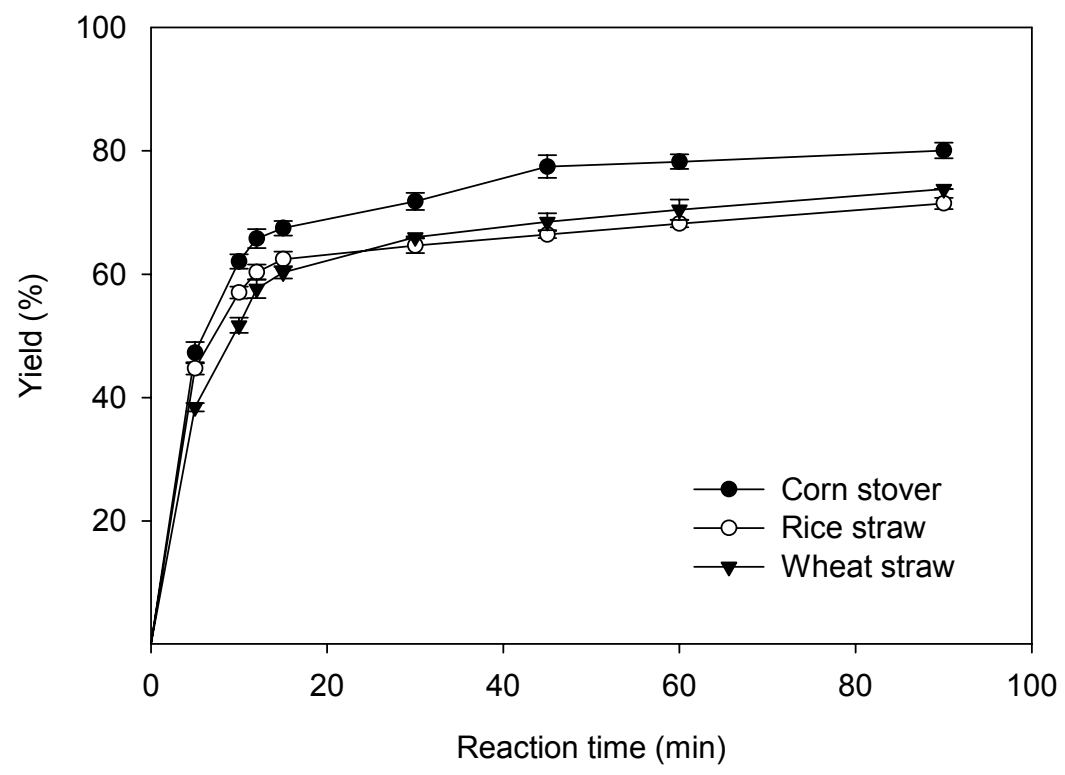

Fig. 3. Liquefaction yield of crop residues when liquefied with mixture of ethylene carbonate and ethylene glycol $(8: 2, \mathrm{w} / \mathrm{w})$ 
Different liquefaction yields among different feedstocks might be caused by the ash content of the biomass feedstock. The cell wall structure should be another factor which affects the liquefaction yield. Corn stover had the lowest ash content of $5.92 \%$, as a result the highest liquefaction yield was obtained when corn stover was liquefied. Rice straw had the highest ash content of $12.47 \%$ and the lowest liquefaction yield was obtained when rice straw was liquefied. Increasing ash content caused lower reaction constants and liquefaction yield.

Table 3. Rate Constants of Different Feedstocks when Liquefied with Ethylene Carbonate and Mixture of Ethylene Carbonate and Ethylene Glycol (8:2, w/w)

\begin{tabular}{ccccc}
\hline $\begin{array}{c}\text { Residue } \\
\text { type }\end{array}$ & $\begin{array}{c}\text { Ethylene } \\
\text { carbonate }\end{array}$ & $\begin{array}{c}\text { Correlation } \\
\text { coefficient }\left(\mathrm{R}^{2}\right)\end{array}$ & $\begin{array}{c}\text { Ethylene carbonate }+ \\
\text { ethylene glycol }\end{array}$ & $\begin{array}{c}\text { Correlation } \\
\text { coefficient }\left(\mathrm{R}^{2}\right)\end{array}$ \\
\hline $\begin{array}{c}\text { Corn stover } \\
\text { Rice straw }\end{array}$ & 0.0884 & 0.9702 & 0.0882 & 0.9643 \\
$\begin{array}{c}\text { Wheat } \\
\text { straw }\end{array}$ & 0.0702 & 0.9762 & 0.0756 & 0.9454 \\
\hline
\end{tabular}

\section{Characterization of Liquefaction Products}

The FTIR spectrum of the liquefied residue of corn stover with ethylene carbonate is shown in Fig 4.
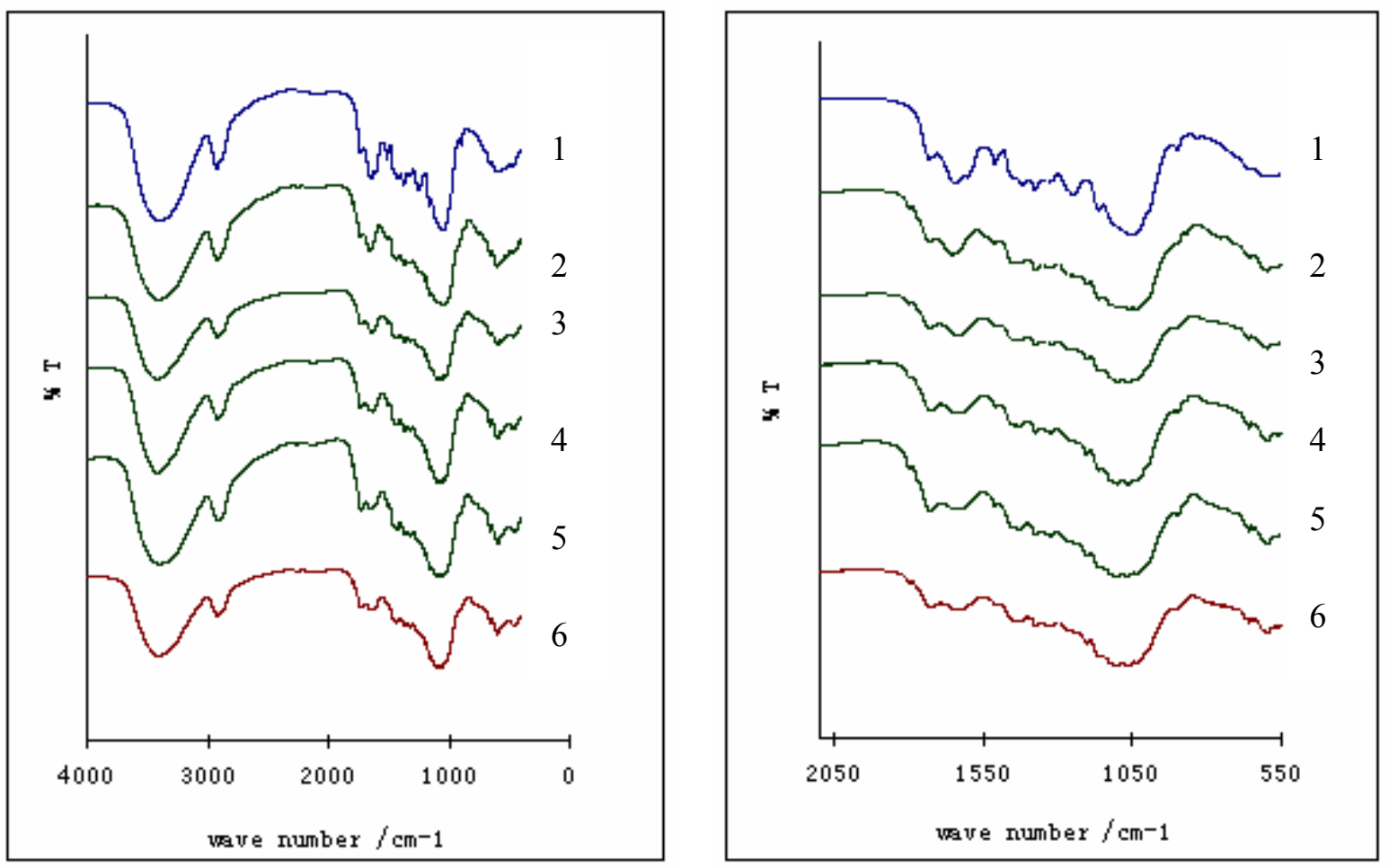

Fig. 4. FTIR spectra of residue liquefied corn stover at different reaction time (1- $0 \mathrm{~min}, 2-5 \mathrm{~min}$, 3- $15 \mathrm{~min}, 4-30 \mathrm{~min}, 5-60 \mathrm{~min}, 6-90 \mathrm{~min}$ ) 
The absorption band at $1732 \mathrm{~cm}^{-1}$ is attributed to the stretching vibration of $\mathrm{C}=\mathrm{O}$ in hemicellulose. The absorption bands at $1648 \mathrm{~cm}^{-1}$ and $1515 \mathrm{~cm}^{-1}$ are attributed to the stretching of the aromatic rings in lignin. The absorption band at $899 \mathrm{~cm}^{-1}$ is attributed to the stretching of $\beta$ glycosidic bond in cellulose. It can be seen from Fig 4 that the absorption intensities of lignin and cellulose decreased substantially, while there was no obvious change for the absorption intensity of hemicellulose. It can be concluded that lignin and cellulose were liquefied prior to hemicellulose and the most significant conversion during liquefaction was observed in lignin. It was reported by Yadama and Ono (1999) that ethylene carbonate would promote the acid-catalyzed solvolysis of cellulose. Ethylene carbonate could be transformed into alcoholic compounds with the release of carbon dioxide during liquefaction. Further analysis, such as with GC/MS, will be helpful to understand the chemical reaction of the liquefaction process.

\section{CONCLUSIONS}

It is concluded that crop residues could be successfully liquefied by solvents of ethylene carbonate, ethylene glycol, and polyethylene glycol with sulfuric acid being used as catalyst. The kinetic studies of the liquefaction process demonstrated that the liquefaction process follows a pseudo-first-order reaction. The rate constant can be used to evaluate the liquefaction rate of the process. When corn stover was liquefied with ethylene carbonate, ethylene glycol, and a mixture of polyethylene glycol and glycerol, the highest liquefaction rate was obtained when ethylene carbonate was used as solvent. Among the three types of crop residues studied, the highest liquefaction yield was obtained with corn stover. The liquefaction yields of wheat straw and rice straw were very close. The physical, chemical and mechanical properties of the obtained liquefied crop residues will be further studied in order to be used as substrates for biomaterial production.

\section{ACKNOWLEDGMENTS}

Financial support by National Natural Science Foundation of China (contract number 30471374) is greatly appreciated.

\section{REFERENCES CITED}

Anon. (2000). China Statistical Yearbook of Agriculture 2000, Beijing, China Agricultural Press, pp: 52.

Chernyak, Y. (2006). "Dielectric constant, dipole moment, and solubility parameters of some cyclic acid esters," J. Chem. Eng. Data 51, 416-418.

Dasappa, S., Sridhar, S. V., Sridhar, G., Paul, P. J., and Mukunda, H. S. (2003). "Biomass gasification - a substitute to fossil fuel for heat application," Biomass and Bioenergy, 
25(6), 637-649.

Kaar, W. E., and Holtzapple, M. T. (2000). "Using lime pretreatment to facilitate the enzymic hydrolysis of corn stover," Biomass and Bioenergy, 18, 189-199.

Kim, T. H., Kim, J. S., Sunwoo, C., and Lee Y. Y. (2003), "Pretreatment of corn stover by aqueous ammonia," Bioresource Technology 90(1), 39-47.

Li, Y., Ruan, R. R., Chen, P. L., Liu, Z., and Pan X. (2004). "Enzymatic hydrolysis of corn stover pretreated by combined dilute alkaline treatment and homogenization" Trans. ASAE 47(3), 821-825.

Mohan, D., Pittman, C. U., Steele, P. H. (2006). "Pyrolysis of wood/biomass for bio-oil: A critical review," Energy and Fuels, 20(3), 848-889.

Montane, D., Farriol, X., Salvado, J., Jollez, P., and Chornet, E. (1998). "Fractionation of wheat straw by steam-explosion pretreatment and alkali delignification. Cellulose pulp and byproducts from hemicellulose and lignin," J. Wood Chem. Technol. 18, 171-191.

Sengwa, R. J., Kaur, K., and Chaudhary, R. (2000). "Dielectric properties of low molecular weight poly(ethylene glycol)s," Polym Int. 49, 599-608.

Shahbazi, A., Li, Y. B., and Mims, M. R. (2005). "Application of sequential aqueous steam treatments to the fractionation of softwood," Appl. Biochem. Biotechnol.121, 973-988.

Shiraishi, N., Shirakawa, K., Kurimoto Y. (1992). "Liquefying lignocellulose substances with polyhydric alcohol," Japanese Pat. Appl. 106128.

Xie, T. and Chen, F. (2005). "Fast liquefaction of bagasse in ethylene carbonate and preparation of epoxy resin from the liquefied product," J. Appl. Poly. Sci. 98, 19611968.

Yamada, T., Ono, H. (1999). "Rapid liquefaction of lignocellulosic waste by using ethylene carbonate," Bioresource Technology 70(1), 61-67.

Yao, Y., Yoshioka, M., and Shiraishi, N. (1996), "Water-absorbing polyurethane foams from liquefied starch,” J. Appl. Polym. Sci. 60, 1939-1949.

Yu, F., Ruan, R., Lin, X., Liu, Y., Fu, R., Li, Y., Chen, P., and Gao, Y. (2006a). "Reaction kinetics of stover liquefaction in recycled stover polyol," Applied Biochemistry and Biotechnology, 129-132. In press.

Yu, F., Ruan, R., Liu, Y., Pan, X., Lin, X., Liu, C., and Chen, P (2006b). "Liquefaction of corn stover and preparation of polyester from the liquefied polyol," Applied Biochemistry and Biotechnology, 129-132. In press.

Yu, S. M. (1982). "Solvolytic liquefaction of wood under mild conditions," PhD thesis, University of California, Berkeley.

Article submitted: September 7, 2006; First round of reviewing completed: October 4, 2006; Revised version accepted: November 4, 2006; Article published: November $20,2006$. 